\title{
Appendicitis mimicking the CT appearance of an appendiceal mucinous neoplasm
}

\author{
Jia Qi Jeremy Soon ${ }^{1 *}$, Syed Aftab ${ }^{1}$, Lianne Lee Ai Ling ${ }^{2}$, Srinivas Anand Swaroop Uppaluri ${ }^{1}$, Shi \\ Xian Shawn Kok ${ }^{1}$ \\ 1. Department of Diagnostic Radiology, Sengkang General Hospital Singapore, Singapore \\ 2. Department of Pathology, Sengkang General Hospital Singapore, Singapore
}

* Correspondence: Jia Qi Jeremy Soon, Department of Diagnostic Radiology, 110 Sengkang E Way, Singapore 544886, Singapore $(\lambda$ jeremy_soon_jq@hotmail.com)

Radiology Case. 2020 Nov; 14(11):26-38 :: $\quad$ DOI: 10.3941/jrcr.v14i11.4081

\begin{abstract}
Occasionally, radiologically diagnosed acute appendicitis is found to harbour underlying appendiceal neoplasm on post-surgical histopathology. Conversely, a situation in which radiologically, the appendix demonstrates features consistent with an underlying tumour but post-operative pathology finds no evidence of neoplastic change is rare. We describe a case of a 50year-old man who presented with a markedly dilated "mass-like" appendix with minimal inflammatory changes on a computed tomography scan. Radiological findings were suspicious for an appendiceal neoplasm/mucocele (i.e. low-grade mucinous neoplasm). However, the postsurgical histopathological diagnosis did not concur with the radiological diagnosis and instead demonstrated findings compatible with acute appendicitis without neoplastic change. In this case report we provide a histopathological correlation and an explanation as to how this may have happened with the hope of helping radiologists avoid this pitfall in the future.
\end{abstract}

\section{CASE REPORT}

\section{CASE REPORT}

A 50-year-old Chinese man presented to the emergency department with symptoms of generalized abdominal pain of 2 days duration. The pain was episodic, crampy, generalized and exacerbated with spicy food. He had no fever, nausea or anorexia. He did not have any significant past medical history. On examination, he was found to have a vague tenderness in the right iliac fossa. Otherwise the abdomen was soft and there were no signs of peritonism. He was afebrile. The full blood count and serum electrolytes were unremarkable. The white blood cell count was $8.17 \times 109 / \mathrm{L}$ (4.5 to $11.0 \times 109 / \mathrm{L})$.
Urinalysis did not reveal any abnormal cell counts, crystals or microorganisms.

From the clinical history, examination and blood investigations, the Alvarado score was 3 . The patient was initially treated for constipation colic with laxatives and analgesia. However, in view of his persistent abdominal pain, a computed tomography (CT) scan of the abdomen and pelvis was requested and performed a day after admission.

The CT scan demonstrated a markedly dilated "masslike" appendix measuring up to $2.0 \mathrm{~cm}$ in diameter that was 
filled with mildly dense fluid with attenuation value of $45 \mathrm{HU}$ (Figure 1). There was strong mural hyperenhancement, but minimal surrounding periappendiceal fat stranding. No perforation or periappendiceal abscess (i.e. rim-enhancing fluid collection) was evident on the scan. A few prominent and borderline enlarged ileocecal lymph nodes measuring up to $1 \mathrm{~cm}$ in short axis diameter were seen. These features were consistent with an appendiceal mucocele with concern for an appendiceal mucinous lesion, favouring a low-grade mucinous neoplasm. In the context of abdominal pain and the presence of these very minor inflammatory changes, superimposed inflammatory process could not be excluded but were deemed to be less likely and this possibility was suggested to the surgical team in charge of the patient.

Working from the diagnosis of an appendiceal mucinous neoplasm with possible superimposed appendicitis, this patient was counselled for a laparoscopic appendicectomy, with possible extension to a right hemicolectomy and mesocolic nodal dissection if extra-appendiceal extension of disease was found. Intraoperatively, the tip and body of the appendix was found to be dilated without evidence of perforation or gangrene. The base of the appendix and the cecum appeared healthy. Eventually, only a laparoscopic appendicectomy was performed. The patient's post-operative recovery was uneventful and he was discharged well after a few days.

The specimen was sent for histological analysis. On gross dissection, the appendix had a serpiginous shape and appeared coiled around itself. The mid-portion of the appendix was dilated to $1.7 \mathrm{~cm}$ in diameter (Figure 2A). Haematoxylin and eosin (H\&E) stain was used to stain the specimen. Under 200 times magnification, mucosal ulceration with a mixed transmural inflammation was seen extending into the periappendiceal fat. The inflammatory infiltrate consisted predominantly of neutrophils with admixed eosinophils, lymphocytes, plasma cells and macrophages (Figure 2B). Under 20 times magnification, scattered, small lymphoid aggregates were seen around the periphery of the appendix. A fibrinous adhesion between segments of the appendiceal serosa was present and associated with reactive subserosal fibroblastic changes (Figure 2C). These findings were in keeping with an acute appendicitis, with suggestion of possible previous inflammation or subacute appendicitis. There was no macroscopic or microscopic evidence of dysplasia. The histological conclusion was acute appendicitis without neoplastic change.

In view of the discordance between the features of the appendix seen on CT and the histological findings, this case was discussed at a multidisciplinary round. It was suggested that due to the coiling of the appendix on itself, it may have resulted in an appearance of a single enlarged dilated lumen. Furthermore, there was likely a sealed perforation between the folded appendix with a small contained fluid collection / abscess formation causing further appendiceal dilatation. Combination of the above findings likely accounted for the "mass-like" appearance of the appendix mimicking an underlying mucinous neoplasm. This is further clarified schematically in Figure 3. On histology, the scattered lymphoid aggregates and reactive fibroblastic changes suggest a more prolonged or subacute course of inflammation, which may have resulted in the milder symptomology (low Alvarado score) and a possible cause of the relative lack of inflammatory changes on the CT scan.

\section{DISCUSSION}

\section{Introduction:}

Radiological diagnosis of acute appendicitis can be confidently performed when its classical features are present on computed tomography (CT). However, in the setting of an abnormal and bulky appearing appendix with only minimal periappendiceal inflammatory changes, neoplastic disease should be considered first and foremost.

We present an unusual case of an appendicitis mimicking a mucinous neoplasm on CT scan. The CT findings of a dilated "mass-like" appendix with minimal surrounding inflammatory changes was highly suggestive of a low-grade mucinous neoplasm. The submitted clinical history and low Alvarado score also pointed away from the diagnosis of acute appendicitis. Therefore, the histology result of acute appendicitis without mucinous neoplasm or dysplasia was unexpected. We discuss the clinical and imaging pitfalls in this peculiar case.

\section{Etiology \& Demographics:}

An appendiceal mucocele is a descriptive term that refers to a dilated appendix due to abnormal mucin content with chronic luminal obstruction [1-3]. They are rare with a reported incidence rate of $0.2-0.3 \%$ of all appendix specimens [4-6] and typically found in patients aged 50-60 years old with a female preponderance [7]. They can be due to either non-neoplastic or neoplastic conditions [1].

A simple mucocele is due to non-neoplastic conditions including mucosal hyperplasia and retention cysts [7] and is often self-limiting with mild appendiceal dilatation. This is because as mucin builds up in the appendix lumen, luminal pressure increases causing atrophy of the mucin secreting epithelial cells, resulting in reduced mucin production and limited appendiceal dilatation [3,5]. On the other hand, neoplastic causes of mucoceles result in more extensive dilatation of the appendix lumen with higher rates of perforation and rupture [3]. Of the group of mucinous neoplasms, they are classified into four types. Namely mucinous adenomas, low-grade appendiceal neoplasms (LAMN), high-grade appendiceal neoplasms (HAMN) and mucinous adenocarcinomas [8,9]. The abnormal mucin secretion from the neoplastic cells and chronic luminal obstruction results in characteristic collections and mucinous deposits that are recognizable on imaging [8]. Most mucinous neoplasms present as mucoceles seen on imaging and are less likely to manifest as appendicitis as compared with the other appendiceal neoplasms due to the chronicity of the luminal obstruction $[1,10]$.

Mucinous neoplasms also have the potential to progress to pseudomyxoma peritonei (PMP). PMP is a condition where there is intraperitoneal accumulation of mucus due to mucinous neoplasia, which can result from dissemination of 
the mucinous neoplastic cells after mucocele rupture into the peritoneal cavity either spontaneously or inadvertently during surgery [10,11]. PMP is more difficult to treat due to peritoneal dissemination and organ invasion.

\section{Clinical and imaging findings:}

Patients with appendiceal mucoceles are often asymptomatic. In patients who have symptoms, the most common complaint is abdominal pain. Other presentations may include nausea, vomiting, or a palpable right iliac fossa mass $[1,2,11]$. As a large part of the symptomology overlaps with acute appendicitis, it can be difficult to differentiate the two based on clinical history and examination alone $[1,5,10,12]$. PMP can present with similar symptoms and additionally with gradually increasing abdominal girth due to accumulation of intraperitoneal mucin [13]. Imaging therefore plays a big part in diagnosing appendiceal mucoceles preoperatively.

A mucocele can be readily diagnosed from CT imaging [2-4]. It is seen as a spherical or elongated, well encapsulated cystic mass with low attenuation extending from the cecum without periappendiceal inflammatory reaction [2-6]. The sizes can vary with reports from $1.5 \mathrm{~cm}$ up to $10 \mathrm{~cm}$ in diameter [2], and an upper threshold of $1.5 \mathrm{~cm}$ has been suggested for radiological consideration of an appendiceal mucocele $[4,5,12]$. Mural calcification is characteristic and may develop as a dystrophic response to chronic inflammation but is not always present $[1-3,6]$. Additional features such as soft tissue nodularity, thickening and wall irregularity are suggestive of underlying malignant neoplasm $[1,5,6,14]$. Simple mucoceles rarely exceed $2.0 \mathrm{~cm}$ in diameter, and a diameter of greater than $2.0 \mathrm{~cm}$ should suggest an underlying neoplastic process and subsequent management should be tailored accordingly $[1,10,11,15]$. Figure $4 \mathrm{E}$ and $\mathrm{F}$ demonstrates a typical case of an appendix mucocele as evident by a markedly dilated and elongated mass-like appearance of the appendix filled with low-density mucinous material with lack of surrounding inflammatory changes. This was histologically confirmed to be a low grade appendiceal neoplasm.

Other imaging modalities may assist in achieving the diagnosis. On ultrasound (US), an appendiceal mucocele appears as a heterogenous cystic mass, and acoustic shadowing from mural calcification may be present $[7,16]$. Layering of the mucin content shows up as internal concentric echogenic layers. This layering is referred to as the "onion skin sign" which is highly specific for appendiceal mucoceles at $100 \%$. However, this is only moderately sensitive for mucoceles at $63 \%[7,17]$. CT is preferred over ultrasound as it is better at seeing the anatomical relations of the mass and at detecting calcifications [3,5]. Magnetic resonance imaging (MRI) provides similar information as CT on the characteristics and anatomical relations of the mass, and may be the preferred option in patients who are pregnant or have adverse reactions to iodinated contrast. A mucocele appears hyperintense on T2 weighted imaging, while its appearance is variable on T1 depending on its mucin content [5,7]. Any extravasated mucin appears hyperintense on $\mathrm{T} 2$, may represent peritoneal implants [7].
In our case report, the patient's histology results of appendicitis without neoplastic change did not concur with the clinical picture and the radiological findings. As mentioned earlier, appendiceal mucoceles and mucinous neoplasms are more common between ages 50 and 60 years. In contrast, although acute appendicitis is seen in all age groups, it is mostly a disease of the younger patient with estimates of 23 to $27 \%$ of all cases occurring between age 10 and 20 years, with decreasing incidence as patient's age group increases $[18,19]$. In addition, the patient's symptoms were non-specific and the only positive symptoms and signs were abdominal pain and tenderness in the right iliac fossa. Using the Alvarado scoring system [20], the patient had only scored 3 points. From the literature, an Alvarado score of 5 and above is a suggested diagnostic cut off point for acute appendicitis [21].

The CT features of the appendix in this case also did not favour typical acute appendicitis. In acute appendicitis, there is appendiceal dilatation above the often-quoted normal limit of $6 \mathrm{~mm}$ seen on imaging [22-24]. However, appendiceal dilatation in simple appendicitis is generally not as pronounced as that seen in an appendiceal mucocele. Furthermore, typical cases of acute appendicitis are often accompanied by significant inflammatory changes including mucosal hyperenhancement, mural thickening, periappendiceal fat stranding and fluid [22-25]. We can see this in Figure 4A and B which depicts a typical case of acute uncomplicated appendicitis in a 25 -year-old man presenting with right iliac fossa pain.

As mentioned before, an appendiceal threshold diameter of $1.5 \mathrm{~cm}$ has been suggested for differentiating an appendiceal mucocele from appendicitis which carries a sensitivity of $83 \%$ and specificity of $93 \%$ [12]. This patient's appendix was dilated up to $2.0 \mathrm{~cm}$ on imaging which is greater than the proposed $1.5 \mathrm{~cm}$ cut off. Furthermore, based on the earlier mentioned cut off diameter of $2 \mathrm{~cm}$ for differentiating simple mucoceles from neoplastic causes, there was a greater likelihood of a mucinous neoplasm. Other imaging hallmarks of appendicitis such as appendiceal wall thickening, mural hyperenhancement and periappendiceal fat stranding [22-25] were minimal. The lack of inflammatory changes and the unusually elongated appearance of the appendix also made an appendiceal abscess to be less likely, as appendiceal abscesses usually present as a loculated fluid collection inseparable from the appendix with extensive surrounding inflammatory changes. A typical case of an appendiceal abscess is shown in Figure 4C and D which appears vastly different than our case.

The combination of the patient's demographics (50 years of age), overall clinical presentation (mild, non-specific symptoms, low Alvarado score) and radiological features (appendiceal dilatation $>2 \mathrm{~cm}$ with minimal inflammation) led to a pre-surgical diagnosis of an appendiceal mucocele with possibility of an underlying mucinous neoplasm. Therefore, the final histology of acute appendicitis without neoplastic change was surprising to both the radiological and surgical teams.

In retrospect, the patient's milder symptoms may have been due to a more prolonged or subacute course of inflammation. It is known that appendiceal inflammation may occasionally occur in a subacute or chronic form, manifesting 
as recurrent or chronic appendicitis [22,26]. From the literature, there is little difference in the CT appearance of recurrent and chronic appendicitis compared to the CT appearance of acute appendicitis. These entities are differentiated by their symptomology and histology [26,27]. Patients with chronic or recurrent appendicitis often have a longer preoperative period of pain and significantly lower white blood cell counts and Alvarado scores as compared to patients with acute appendicitis [26], which was the case in our patient. Histological features that suggest chronic or subacute appendicitis include chronic appendiceal inflammatory changes such as lymphocytic plasma cell infiltration, foreign body giant cell reaction, fibrosis and granulomatous reaction [26,27]. Some of these histological features were indeed present in our patient's appendix specimen, namely the scattered lymphoid aggregates, fibrinous adhesions and reactive subserosal fibroblastic changes. The inflammatory infiltrate consisted predominantly of neutrophils which was consistent with acute appendicitis, but also contained other cells including eosinophils, lymphocytes, plasma cells and macrophages that indicated an element of chronic inflammation. From the histological standpoint, it is entirely possible that the patient may have had milder symptoms with a more prolonged course of appendiceal inflammation. Further history could have been taken from the patient for correlation with prior episodes or recurrent or chronic abdominal pain.

As was seen on gross examination of the specimen, the appendix coiling around itself causing two lumens to appear as a single dilated lumen is a possible explanation for the dilated appearance on CT. It is also possible that a sealed perforation into itself may have combined the two lumens into a single dilated one. The fibroblastic changes seen on histology may also have helped to keep any potential perforation localized within the appendix, resulting in relative lack of extraappendiceal inflammatory changes. Thus, we theorize that the patient may have had a subacute or chronic course of appendiceal inflammation, along with a possible sealed perforation of the appendix that resulted in this case of appendicitis mimicking the appearance and presentation of an appendiceal mucinous neoplasm.

\section{Treatment \& Prognosis:}

It is important to identify appendiceal mucoceles early due to the potential of malignancy $[1,6,14]$ and the worrying complication of pseudomyxoma peritonei (PMP) $[3,4,6]$. The surgical management of an appendiceal mucocele is guided by the likely underlying cause. Intraoperative frozen section may be done after laparoscopic appendicectomy to confirm a simple or benign pathology, or to diagnose a tumour [3]. Simple mucoceles, benign adenomas and low grade appendiceal mucinous neoplasms with disease confined to the appendix can possibly be managed with a laparoscopic appendicectomy [8]. LAMN with evidence of local extension will require a right hemicolectomy and lymph node dissection, as it is with HAMN and mucinous adenocarcinomas $[7,8]$. If there is evidence of peritoneal spread or PMP, the gold standard for treatment will include complete cytoreductive surgery (CRS) and hyperthermic intraperitoneal chemotherapy (HIPEC) [3], with a reported 5 year survival of $86 \%$ after successful therapy [28]. However this option can be technically challenging and associated with high rates of complications and need for multi-organ resection in patients with extensive disease, thus requiring careful patient selection and limiting the candidates. [28]. Overall the 5 year survival has been reported at $63 \%$ for low grade PMP and $23 \%$ for high grade PMP [29].

On the other hand, treatment of acute appendicitis boils down to early appendicectomy and treatment of any infective complications, namely postoperative wound infections and intraabdominal abscesses. Antibiotic use has been shown to reduce the rates of these complications, although its routine use for patients after simple appendicectomies is controversial. Intraabdominal abscesses are treated with antibiotics and may be drained surgically or under radiological guidance $[18,30]$. Diagnosed cases of recurrent or chronic appendicitis are also similarly managed with appendicectomies and patients often show resolution of symptoms after surgery. In cases where the patient's symptoms resolve spontaneously without surgery, it may be possible to opt for a conservative approach. However, this is usually not recommended as early appendicectomy can help to prevent later complications in event of future recurrence of disease [26].

Due to the preoperative diagnosis of an appendiceal mucinous neoplasm, the patient in this case was counselled for laparoscopic appendicectomy with possible extension to an open right hemicolectomy depending on the intraoperative findings. The surgical resection was planned carefully as any spillage of appendiceal content into the peritoneum could potentially progress and lead to PMP. As there was no evidence of extra-appendiceal disease during surgery, only a laparoscopic appendicectomy was performed which turned out to be the appropriate treatment in light of the final histological diagnosis of appendicitis. Patient's post-operative recovery was unremarkable.

\section{Differential Diagnosis:}

We discuss briefly about the possible differential diagnoses of a dilated appendix as seen in this case.

\section{Appendiceal mucocele}

The main differential for this case is an appendiceal mucocele from underlying low-grade mucinous neoplasm as discussed in this case report.

Acute appendicitis, appendiceal perforation and abscess

As was the case in this patient, appendicitis is an important differential to consider. Appendicitis is common, with a reported incidence of 9.4 cases per 10,000 [19]. It is more likely to occur in the younger age groups with a male preponderance [19]. Although there is an overlap of imaging features between acute appendicitis and appendiceal mucoceles, certain clues on imaging can help differentiate the two. Acute appendicitis often has smaller luminal dilatation and a greater presence of inflammatory changes as compared with an appendiceal mucocele as discussed in the previous sections. Simple appendicitis can be treated surgically with a laparoscopic appendicectomy [18].

If left untreated, the appendiceal inflammation will eventually progress to appendiceal wall ischemia and necrosis 
resulting in perforation [22,31]. The most common complication of appendiceal perforation is a periappendiceal abscess which appears as a loculated rim enhancing fluid collection [22,32]. Periappendiceal abscesses are kept localized due to the formation of periappendiceal fibrinous adhesions prior to rupture [22,31]. However, after appendiceal perforation and development of an appendiceal inflammatory mass, it will be more difficult to differentiate non-tumoral appendicitis from tumoral appendicitis on imaging [33,34]. Appendiceal dilatation may also have reduced due to perforation [31] and will not be a reliable marker.

Although less sensitive, US is able to visualize the appendix diameter, wall thickness and presence of appendicoliths to support the diagnosis. Colour doppler can also demonstrate hypervascularity in early appendicitis and hypovascularity in later stages of appendix necrosis [35]. MRI is also an alternative to $\mathrm{CT}$ if there are concerns about ionizing radiation in paediatric or pregnant populations. An inflamed and oedematous appendix appears hyperintense on T2weighted imaging. Other supporting features of appendiceal diameter, wall thickness and periappendiceal fluid can also be appreciated [36].

\section{Caecal Diverticulitis}

CT features of caecal diverticulitis include pericaecal fat stranding, wall thickening, visualization of diverticula and potentially abscesses. Due to the proximity of the appendix, caecal diverticulitis can be misdiagnosed as appendicitis if there is associated reactive inflammatory changes of the appendix. Well circumscribed abscesses may also be mistaken for a dilated appendix or an appendiceal mucocele [7,37]. On US, aside from the wall thickening of the colon, inflamed mesentery and omentum around the area of diverticulitis appear as hyperechoic uncompressible tissue [38]. On MRI, thickened and inflamed colonic wall appears hyperintense on T2-weighted imaging. Surrounding inflammatory changes show up as low intensity strands on T1-weight imaging and hyperintense on T2-weighted imaging. Visualizing a normal appendix on MRI can help to confirm the diagnosis [39].

\section{Caecal and appendiceal carcinomas}

Caecal carcinomas may occlude the appendiceal lumen leading to dilatation of an otherwise normal appendix. CT features include either a mass like appearance or abnormal wall thickening of the caecum at the appendiceal origin [7]. The occlusion of the appendicular lumen may also cause secondary appendicitis, or the tumour itself may perforate imitating appendicitis. These are more common in elderly than in younger populations [22]. On US, the lack of movement in real-time scanning and the loss of a layered structure of colonic wall supports the diagnosis [40]. MRI is also able to demonstrate the tumour characteristics seen on CT.

\section{Right adnexal cystic masses in females}

Ovarian and fallopian tube cysts, tubo-ovarian complex lesions and abscesses appear as well-circumscribed or loculated cystic structures which may be closely related to the caecum on CT imaging. They can appear similarly to a perforated appendicitis or an appendicitis with phlegmon / abscess, thus making it difficult to determine the correct radiological diagnosis $[7,41,42]$. The appearance of these various lesions on ultrasound depends on the underlying pathology. Haemorrhagic corpus luteum cysts may appear to contain homogenous or heterogenous echogenic content, while teratomas may appear to contain hyperechoic masses with acoustic shadowing. Tubo-ovarian abscesses appear as thick walled complex cysts with solid areas which may become cystic as they progress [43]. MRI may reveal enlarged and oedematous ovaries or fluid collections in the adnexa which contain hyperintense fluid on T2-weighted imaging [36].

\section{TEACHING POINT}

An appendiceal mucocele due to underlying mucinous neoplasm is an important consideration when a markedly dilated appendix is seen on imaging as early preoperative diagnosis will alter surgical approach and improve clinical outcomes. However due to the inherent rarity of appendiceal mucoceles and mucinous neoplasms, radiologists should be well versed with the various mimics, pitfalls and differentials that can arise, one of which is a "mass-like" appearance of appendicitis.

\section{REFERENCES}

1. Pickhardt PJ, Levy AD, Rohrmann CA, Kende AI. Primary neoplasms of the appendix: radiologic spectrum of disease with pathologic correlation. Radiographics?: a review publication of the Radiological Society of North America, Inc 2003;23:645-62 PMID: 12740466.

2. Zissin R, Gayer G, Kots E, Apter S, Peri M, ShapiroFeinberg M. Imaging of mucocoele of the appendix with emphasis on the CT findings: a report of 10 cases. Clinical radiology 1999;54:826-32 PMID: 10619300.

3. Rymer B, Forsythe RO, Husada G. Mucocoele and mucinous tumours of the appendix: A review of the literature. International journal of surgery (London, England) 2015;18:132-5 PMID: 25917270.

4. Karakaya K, Barut F, Emre A-U, et al. Appendiceal mucocele: case reports and review of current literature. World journal of gastroenterology 2008;14:2280-3 PMID: 18407611.

5. Lee NK, Kim S, Kim HS, et al. Spectrum of mucinproducing neoplastic conditions of the abdomen and pelvis: cross-sectional imaging evaluation. World journal of gastroenterology 2011;17:4757-71 PMID: 22147976.

6. Wang H, Chen Y-Q, Wei R, et al. Appendiceal mucocele: A diagnostic dilemma in differentiating malignant from benign lesions with CT. AJR American journal of roentgenology 2013;201:W590-5 PMID: 24059397.

7. Van Hooser A, Williams TR, Myers DT. Mucinous appendiceal neoplasms: pathologic classification, clinical implications, imaging spectrum and mimics. Abdominal radiology (New York) 2018;43:2913-22 PMID: 29564494. 
8. Leonards LM, Pahwa A, Patel MK, Petersen J, Nguyen MJ, Jude CM. Neoplasms of the Appendix: Pictorial Review with Clinical and Pathologic Correlation. Radiographics?: a review publication of the Radiological Society of North America, Inc 2017;37:1059-83 PMID: 28598731.

9. Carr NJ, Cecil TD, Mohamed F, et al. A Consensus for Classification and Pathologic Reporting of Pseudomyxoma Peritonei and Associated Appendiceal Neoplasia: The Results of the Peritoneal Surface Oncology Group International (PSOGI) Modified Delphi Process. The American journal of surgical pathology 2016;40:14-26 PMID: 26492181.

10. Karande GY, Chua WM, Yiin RSZ, Wong KM, Hedgire $\mathrm{S}$, Tan TJ. Spectrum of computed tomography manifestations of appendiceal neoplasms: acute appendicitis and beyond. Singapore medical journal 2019;60:173-82 PMID: 31069398.

11. Dixit A, Robertson JHP, Mudan SS, Akle C. Appendiceal mucocoeles and pseudomyxoma peritonei. World journal of gastroenterology 2007;13:2381-4 PMID: 17511043

12. Lien W, Huang S, Chi C, et al. Appendiceal outer diameter as an indicator for differentiating appendiceal mucocele from appendicitis. The American journal of emergency medicine 2006;24:801-5 PMID: 17098100.

13. Esquivel J, Sugarbaker PH. Clinical presentation of the Pseudomyxoma peritonei syndrome. The British journal of surgery 2000;87:1414-8 PMID: 11044169.

14. Lim HK, Lee WJ, Kim SH, Kim B, Cho JM, Byun JY. Primary mucinous cystadenocarcinoma of the appendix: CT findings. AJR American journal of roentgenology 1999;173:1071-4 PMID: 10511181

15. Schmutzer KJ, Bayar M, Zaki AE, Regan JF, Poletti JB. Tumors of the appendix. Diseases of the colon and rectum 1975;18:324-31 PMID: 1126268.

16. Kim SH, Lim HK, Lee WJ, Lim JH, Byun JY. Mucocele of the appendix: ultrasonographic and CT findings. Abdominal imaging 1998;23:292-6 PMID: 9569300.

17. Kameda T, Kawai F, Taniguchi N, Omoto K, Kobori Y, Arakawa K. Evaluation of whether the ultrasonographic onion skin sign is specific for the diagnosis of an appendiceal mucocele. Journal of medical ultrasonics (2001) 2014;41:43943 PMID: 27278024.

18. Humes DJ, Simpson J. Acute appendicitis. BMJ (Clinical research ed) 2006;333:530-4 PMID: 16960208.

19. Buckius MT, McGrath B, Monk J, Grim R, Bell T, Ahuja V. Changing epidemiology of acute appendicitis in the United States: study period 1993-2008. The Journal of surgical research 2012;175:185-90 PMID: 22099604.

20. Alvarado A. A practical score for the early diagnosis of acute appendicitis. Annals of emergency medicine 1986;15:557-64 PMID: 3963537.
21. Ohle R, O'Reilly F, O'Brien KK, Fahey T, Dimitrov BD. The Alvarado score for predicting acute appendicitis: a systematic review. BMC medicine 2011;9:139 PMID: 22204638 .

22. Pinto Leite N, Pereira JM, Cunha R, Pinto P, Sirlin C. CT evaluation of appendicitis and its complications: imaging techniques and key diagnostic findings. AJR American journal of roentgenology 2005;185:406-17 PMID: 16037513.

23. Daly CP, Cohan RH, Francis IR, Caoili EM, Ellis JH, Nan B. Incidence of acute appendicitis in patients with equivocal CT findings. AJR American journal of roentgenology 2005;184:1813-20 PMID: 15908536.

24. Kitagawa M, Kotani T, Miyamoto Y, et al. Noncontrast and contrast enhanced computed tomography for diagnosing acute appendicitis: A retrospective study for the usefulness. Journal of radiology case reports 2009;3:26-33 PMID: 22470667

25. Rhea JT, Halpern EF, Ptak T, Lawrason JN, Sacknoff R, Novelline RA. The status of appendiceal CT in an urban medical center 5 years after its introduction: experience with 753 patients. AJR American journal of roentgenology 2005;184:1802-8 PMID: 15908534.

26. See TC, Watson CJE, Arends MJ, Ng CS. Atypical appendicitis: the impact of CT and its management. Journal of medical imaging and radiation oncology 2008;52:140-7 PMID: 18373805.

27. Rao PM, Rhea JT, Novelline RA, McCabe CJ. The computed tomography appearance of recurrent and chronic appendicitis. The American journal of emergency medicine 1998;16:26-33 PMID: 9451309.

28. Benhaim L, Faron M, Gelli M, et al. Survival after complete cytoreductive surgery and HIPEC for extensive pseudomyxoma peritonei. Surgical oncology 2019;29:78-83 PMID: 31196498.

29. Carr NJ, Finch J, Ilesley IC, et al. Pathology and prognosis in pseudomyxoma peritonei: a review of 274 cases. Journal of clinical pathology 2012;65:919-23 PMID: 22718846.

30. Andersen BR, Kallehave FL, Andersen HK. Antibiotics versus placebo for prevention of postoperative infection after appendicectomy. The Cochrane database of systematic reviews 2005:CD001439 PMID: 16034862.

31. Hopkins KL, Patrick LE, Ball TI. Imaging findings of perforative appendicitis: a pictorial review. Pediatric radiology 2001;31:173-9 PMID: 11297081.

32. Birnbaum BA, Jeffrey RB. CT and sonographic evaluation of acute right lower quadrant abdominal pain. AJR American journal of roentgenology 1998;170:361-71 PMID: 9456947.

33. Teixeira FJR, Couto Netto SD do, Akaishi EH, Utiyama EM, Menegozzo CAM, Rocha MC. Acute appendicitis, inflammatory appendiceal mass and the risk of a hidden malignant tumor: a systematic review of the literature. World 
journal of emergency surgery?: WJES 2017;12:12 PMID: 28286544.

34. Bennett GL, Tanpitukpongse TP, Macari M, Cho KC, Babb JS. CT diagnosis of mucocele of the appendix in patients with acute appendicitis. AJR American journal of roentgenology 2009;192:W103-10 PMID: 19234237.

35. Mostbeck G, Adam EJ, Nielsen MB, et al. How to diagnose acute appendicitis: ultrasound first. Insights into imaging 2016;7:255-63 PMID: 26883138.

36. Mervak BM, Wilson SB, Handly BD, Altun E, Burke LM. MRI of acute appendicitis. Journal of magnetic resonance imaging?: JMRI 2019;50:1367-76 PMID: 30883988.

37. Balthazar EJ, Megibow AJ, Gordon RB, Hulnick D. Cecal diverticulitis: evaluation with CT. Radiology 1987;162:79-81 PMID: 3786788.

38. Puylaert JBCM. Ultrasound of colon diverticulitis. Digestive diseases (Basel, Switzerland) 2012;30:56-9 PMID: 22572686 .

39. Cobben LPJ, Groot I, Blickman JG, Puylaert JBCM. Right colonic diverticulitis: MR appearance. Abdominal imaging 2003;28:794-8 PMID: 14753592.

40. Shirahama M, Koga T, Ishibashi H, Uchida S, Ohta Y. Sonographic features of colon carcinoma seen with highfrequency transabdominal ultrasound. Journal of clinical ultrasound?: JCU 1994;22:359-65 PMID: 8071453.

41. Kalu E, Croucher C. Appendiceal mucocele: a rare differential diagnosis of a cystic right adnexal mass. Archives of gynecology and obstetrics 2005;271:86-8 PMID: 15316825.

42. Dragoumis K, Mikos T, Zafrakas M, et al. Mucocele of the vermiform appendix with sonographic appearance of an adnexal mass. Gynecologic and obstetric investigation 2005;59:162-4 PMID: 15687730.

43. Smorgick N, Maymon R. Assessment of adnexal masses using ultrasound: a practical review. International journal of women's health 2014;6:857-63 PMID: 25285023. 

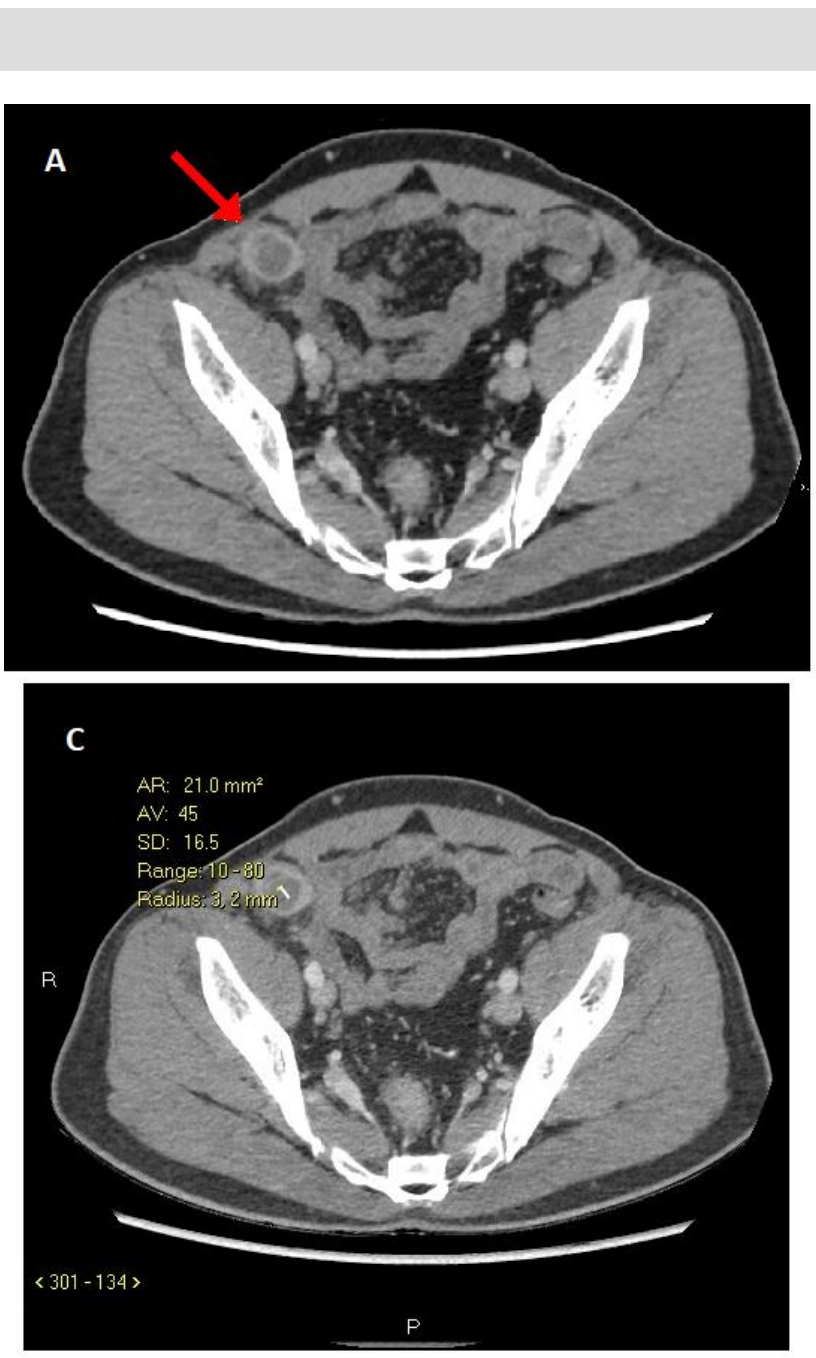

\section{FIGURES}

Figure 1: 50-year-old man with a dilated appendix on CT scan.

FINDINGS: CT demonstrated a dilated blind ending tubular structure arising from the caecal pole dilated up to $2.0 \mathrm{~cm}$ and distended with mildly dense fluid ( $45 \mathrm{HU})$ representing the appendix (red arrows). There was strong mural enhancement but minimal surrounding periappendiceal fat stranding. Findings were concerning for an appendiceal mucinous lesion, favouring low grade. Subfigure C demonstrates the ROI of the "mass-like" appendix.

TECHNIQUE: Contrast enhanced CT abdomen pelvis with axial and coronal reformats. CT scan settings were 3.00mm slice thickness at $140 \mathrm{kV}$ and $320 \mathrm{~mA}$. $70 \mathrm{ml}$ of Omnipaque 350 given. 

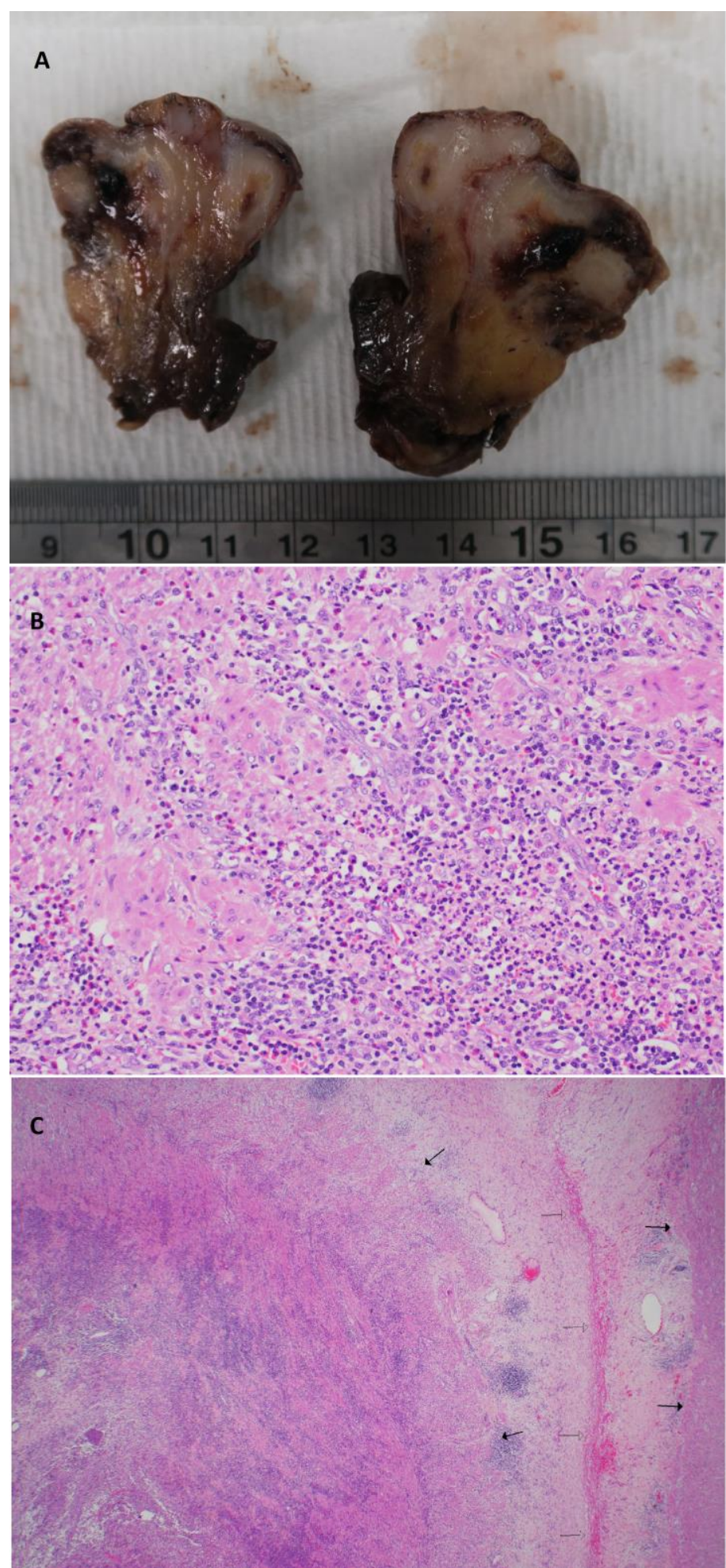

Figure 2 (left): 50-year-old man with a dilated appendix on CT scan.

Figure $2 \mathrm{~A}$ shows the macroscopic view of the cut section of appendix with dilated mid-portion of appendix. The appendix appears coiled around itself.

Figure 2B is the histological slide showing the mixed acute and chronic inflammation within muscularis propria $(\mathrm{H} \& \mathrm{E}$, X200 magnification).

Figure $2 \mathrm{C}$ demonstrates the transmural inflammation of the appendix with fibrinous adhesion (arrow outline) between two segments of the appendix. The external aspect of the muscularis propria is indicated by the black solid arrows. (H\&E, X20 magnification) 


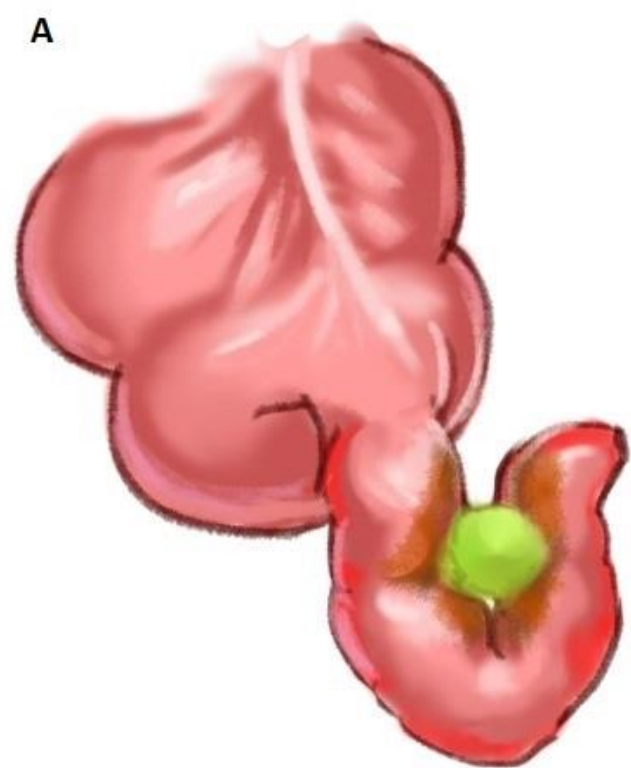

B
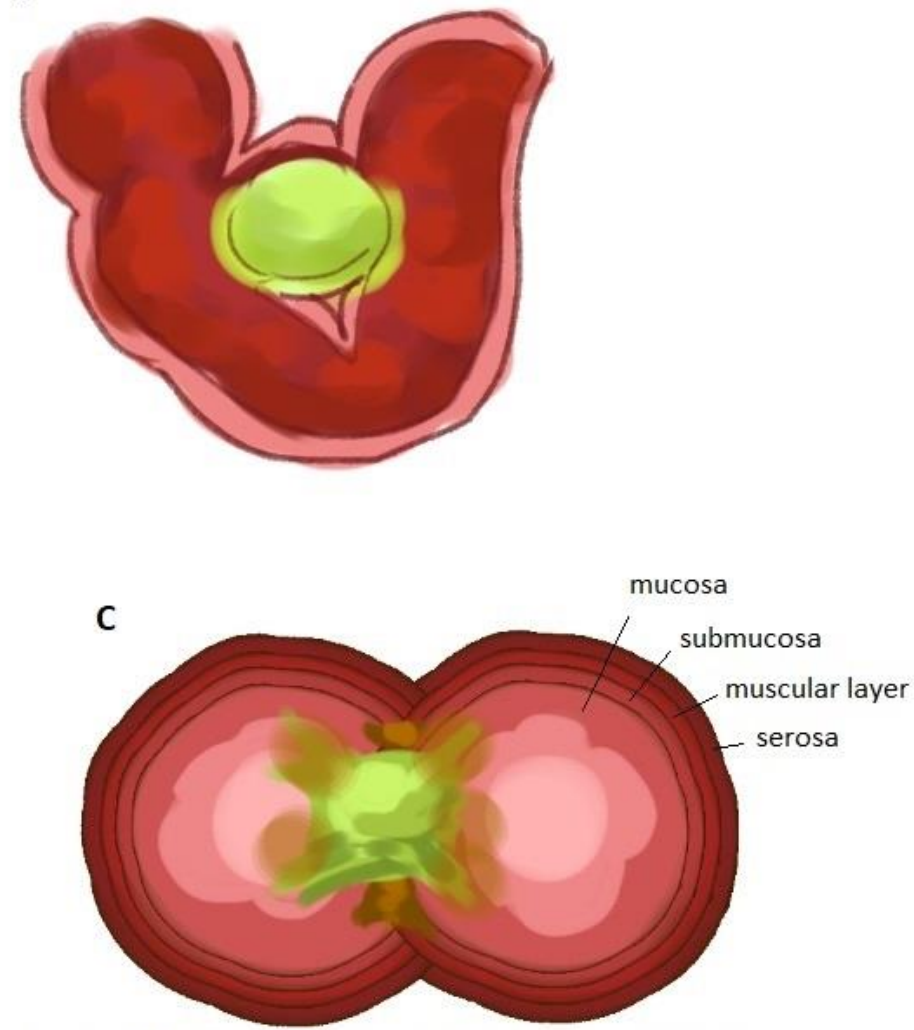

Transmural ulceration leading to a sealed perforation / abscess

Figure 3: Illustration of the appendix coiling on itself with a sealed perforation, abscess formation and the two appendiceal lumens appearing as a single dilated and enlarged lumen, resulting in a "mass-like" appearance. 3A demonstrates the gross appearance while 3B and 3C show the coronal and axial cross sections respectively. Illustrations courtesy of Ms. Lim Wei Ning. 

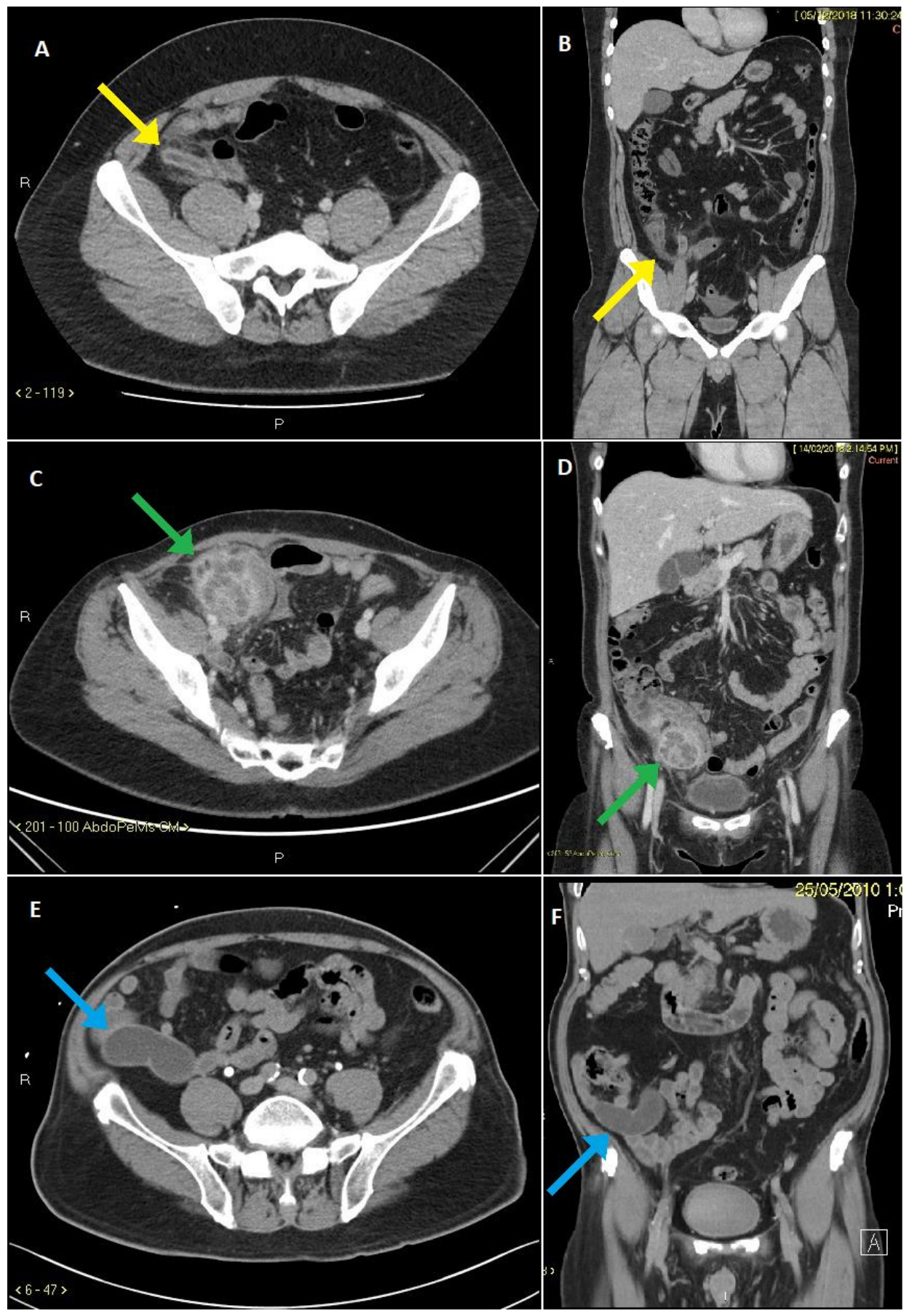

Figure 4: 3 additional cases included for comparison. (A and B) A 25-year-old man with typical acute appendicitis. (C and D) A 54-year-old lady with an appendiceal abscess. (E and F) A 72-year-old man with a low grade appendiceal mucinous neoplasm.

\section{FINDINGS:}

(A and B) CT showed a dilated fluid filled appendix with mural thickening and enhancement and periappendiceal fat stranding (yellow arrow).

(C and D) CT demonstrated a large rim enhancing loculated cystic collection at the appendix with periappendiceal fat stranding (green arrow).

(E and F) CT showed a large circumscribed thin walled cystic lesion in right iliac fossa arising from the appendix (blue arrow). No enhancing solid component or surrounding inflammation was identified.

\section{TECHNIQUE:}

(A and B) Toshiba Aquilion PRIME CT scanner. Slice width $3.00 \mathrm{~mm} .120 \mathrm{kVp}$. Portal venous phase. Axial and coronal reformats. Omnipaque $350(80 \mathrm{ml}$ at $2.0 \mathrm{ml} / \mathrm{s})$.

(C and D) Philips iCT 256. Slice width $3.00 \mathrm{~mm} .120 \mathrm{kVp}$. Portal venous phase. Axial and coronal reformats. Omnipaque 350 ( $75 \mathrm{ml}$ at $1.4 \mathrm{ml} / \mathrm{s}$ ).

(E and F) Siemens SOMATOM Definition. Slice width $3.00 \mathrm{~mm} .120 \mathrm{kVp}$. Axial and coronal reformats. Omnipaque 350 (75 ml at $1.5 \mathrm{ml} / \mathrm{s}$ ). 


\begin{tabular}{|c|c|c|c|}
\hline & $\begin{array}{l}\text { Features on contrast enhanced CT } \\
\text { imaging }\end{array}$ & Features on US & Features on MRI \\
\hline $\begin{array}{l}\text { Appendiceal } \\
\text { mucocele }\end{array}$ & $\begin{array}{l}\text { - Dilated appendix }>1.5 \mathrm{~cm} \\
\text { - Spherical or elongated, well } \\
\text { encapsulated cystic mass extending } \\
\text { from the caecum } \\
\text { - No periappendiceal inflammatory } \\
\text { reaction } \\
\text { - Mural calcification may or may } \\
\text { not be present }\end{array}$ & $\begin{array}{l}\text { - Appears as a heterogenous } \\
\text { cystic mass } \\
\text { - Acoustic shadowing from } \\
\text { calcifications } \\
\text { - "Onion skin sign: from } \\
\text { layering of mucin }\end{array}$ & $\begin{array}{l}\text { - Right iliac fossa cystic mass } \\
\text { - Hyperintense on T2 weighted } \\
\text { imaging } \\
\text { - Has a variable appearance on } \\
\text { T1 weighted imaging depending } \\
\text { on mucin content but is usually } \\
\text { hypointense }\end{array}$ \\
\hline Appendicitis & $\begin{array}{l}\text { - Dilated appendix }>6 \mathrm{~mm} \\
\text { - Appendiceal wall thickening }> \\
\text { 3mm, hyperenhancement } \\
\text { - Periappendiceal fat stranding } \\
\text { - Appendicoliths may or may not be } \\
\text { present }\end{array}$ & $\begin{array}{l}\text { - Non-compressible dilated } \\
\text { appendix }>6 \mathrm{~mm} \\
\text { - Colour doppler may } \\
\text { demonstrate mural hyperaemia } \\
\text { - Appendicoliths are hyperechoic } \\
\text { with acoustic shadowing }\end{array}$ & $\begin{array}{l}\text { - Dilated appendix } \\
\text { - Appendiceal wall thickening } \\
\text { - Periappendiceal fluid } \\
\text { - Inflammation and oedema of } \\
\text { the appendix appear hyperintense } \\
\text { on T2 weighted imaging }\end{array}$ \\
\hline $\begin{array}{l}\text { Caecal } \\
\text { diverticulitis }\end{array}$ & $\begin{array}{l}\text { - Visualization of diverticula } \\
\text { - Caecal wall thickening } \\
\text { - Pericaecal fat stranding } \\
\text { - Well circumscribed abscesses may } \\
\text { be mistaken for a dilated appendix }\end{array}$ & $\begin{array}{l}\text { - Bowel outpouchings with some } \\
\text { acoustic shadowing } \\
\text { - Inflamed mesentery and } \\
\text { omentum appear as hyperechoic } \\
\text { uncompressible tissue } \\
\text { - Thickened bowel wall }\end{array}$ & $\begin{array}{l}\text { - Findings similar to that in CT: } \\
\text { presence of diverticula, thickened } \\
\text { caecal wall and pericolic } \\
\text { stranding } \\
\text { - Thickened and inflamed colonic } \\
\text { wall appears hyperintense on T2 } \\
\text { weighted imaging }\end{array}$ \\
\hline $\begin{array}{l}\text { Caecal and } \\
\text { appendicular } \\
\text { carcinomas }\end{array}$ & $\begin{array}{l}\text { - Irregular caecal/appendicular mass } \\
\text { - Obstruction of appendiceal orifice } \\
\text { may result in a dilated appendix } \\
\text { without periappendiceal } \\
\text { inflammation } \\
\text { - Enlarged lymph nodes due to } \\
\text { metastasis }\end{array}$ & $\begin{array}{l}\text { - Irregular caecal/appendicular } \\
\text { mass } \\
\text { - Loss of normal layered } \\
\text { structure of colonic wall } \\
\text { - Lack of colonic wall movement } \\
\text { and peristalsis in real time } \\
\text { imaging }\end{array}$ & $\begin{array}{l}\text { - Findings similar to that in CT } \\
\text { - Irregular caecal/appendicular } \\
\text { mass } \\
\text { - Nodal involvement may be seen }\end{array}$ \\
\hline $\begin{array}{l}\text { Right adnexal } \\
\text { cystic masses }\end{array}$ & $\begin{array}{l}\text { - Well circumscribed cystic } \\
\text { structures in the right adnexa } \\
\text { - If closely opposed to the caecum, } \\
\text { may mimic a dilated appendix }\end{array}$ & $\begin{array}{l}\text { - Appearance depends pathology } \\
\text { - Corpus luteum cysts may } \\
\text { contain homogenous or } \\
\text { heterogenous echogenic content } \\
\text { - Tubo-ovarian abscesses may } \\
\text { contain both solid and cystic } \\
\text { components }\end{array}$ & $\begin{array}{l}\text { - Fluid collections in adnexa that } \\
\text { are hyperintense on T2 } \\
\text { - Corpus luteum cysts seen as } \\
\text { round or oval adnexal lesions } \\
\text { - Tubo-ovarian abscesses seen as } \\
\text { thick-walled fluid filled pelvic } \\
\text { masses }\end{array}$ \\
\hline
\end{tabular}

Table 1: Differential diagnosis table for a dilated appendix seen on imaging. 


\begin{tabular}{|l|l|l|}
\hline & Appendiceal Mucocele & Appendicitis \\
\hline Aetiology & $\begin{array}{l}\text { Abnormal mucin production and chronic luminal } \\
\text { obstructions results in accumulation of mucin and } \\
\text { abnormal dilatation of the appendix. Can be due to non- } \\
\text { neoplastic conditions or mucinous neoplasms. }\end{array}$ & $\begin{array}{l}\text { Appendiceal luminal obstruction } \\
\text { resulting in fluid accumulation and } \\
\text { inflammation. }\end{array}$ \\
\hline Incidence & Rare. 0.2-0.3\% of all appendix specimens & Common. 11 cases per 10,000 per year. \\
\hline Gender ratio & Slight female preponderance & Slight male preponderance \\
\hline Age predilection & Mostly between age 50-60 years & $\begin{array}{l}\text { Younger patients. Mostly between age } \\
10-20 \text { years }\end{array}$ \\
\hline Risk factors & Female sex & Younger age, male sex \\
\hline Treatment & $\begin{array}{l}\text { Surgical options depend on underlying aetiology and } \\
\text { includes appendicectomy or right hemicolectomy. }\end{array}$ & Appendicectomy \\
\hline Prognosis & $\begin{array}{l}\text { Prognosis depends on underlying aetiology. Benign } \\
\text { aetiologies carry good prognosis while neoplastic } \\
\text { conditions have high rates of recurrence and potential to } \\
\text { progress to PMP which carries worse prognosis. }\end{array}$ & Good if diagnosed and treated early \\
\hline Findings on imaging & $\begin{array}{l}\text { CT scan: a spherical or elongated, well encapsulated } \\
\text { cystic mass with low attenuation extending from the } \\
\text { cecum without periappendiceal inflammatory reaction. } \\
\text { Calcification may or may not be present. }\end{array}$ & $\begin{array}{l}\text { CT scan: Appendiceal dilatation, mural } \\
\text { thickening and hyperenhancement, } \\
\text { periappendiceal fat stranding. }\end{array}$ \\
\hline
\end{tabular}

Table 2: Summary table for appendiceal mucocele and appendicitis.

\section{ABBREVIATIONS}

$\mathrm{CT}=$ Computed tomography

HAMN = High-grade appendiceal mucinous neoplasm

LAMN = Low-grade appendiceal mucinous neoplasm

PMP = Pseudomyxoma peritonei

\section{Online access}

This publication is online available at: www.radiologycases.com/index.php/radiologycases/article/view/4081

\section{Peer discussion}

\section{KEYWORDS}

Appendix; Appendicitis; Chronic appendicitis; Subacute appendicitis; Appendiceal mucocele; appendiceal mucinous neoplasm; CT Abdomen Pelvis

\section{ACKNOWLEDGEMENTS}

Special thanks to Ms. Lim Wei Ning for providing digital illustrations. We would also like to acknowledge Dr. Chea Yen Wei, Dr. Clement Chan, Dr. David Lim Yuri and Dr. Anand Chidambaram Viswanath for their contributions in providing cases for comparison relevant in this case report.
Discuss this manuscript in our protected discussion forum at: www.radiolopolis.com/forums/JRCR

\section{Interactivity}

This publication is available as an interactive article with scroll, window/level, magnify and more features. Available online at www.RadiologyCases.com

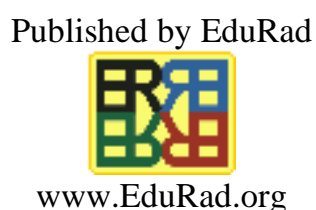

www.EduRad.org 